\title{
Universiteit
}

Leiden

The Netherlands

\section{The effects of soil eutrophication propagate to higher trophic levels}

Poyry, J.; Carvalheiro, L.G.; Heikkinnen, R.K.; Kühn, I.; Kuussaari, M.; Schweiger, O.; ... ; Franzen, M.

\section{Citation}

Poyry, J., Carvalheiro, L. G., Heikkinnen, R. K., Kühn, I., Kuussaari, M., Schweiger, O., ... Franzen, M. (2016). The effects of soil eutrophication propagate to higher trophic levels. Global Ecology And Biogeography, 26(1), 18-30. doi:10.1111/geb.12521

Version: $\quad$ Publisher's Version

License: $\quad$ Licensed under Article 25fa Copyright Act/Law (Amendment Taverne)

Downloaded from: https://hdl.handle.net/1887/3197804

Note: To cite this publication please use the final published version (if applicable). 


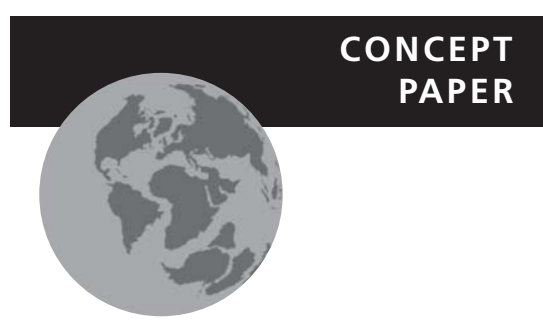

The effects of soil eutrophication
propagate to higher trophic levels

Juha Pöyry $^{1 \star}$, Luísa G. Carvalheiro ${ }^{2,3}$, Risto K. Heikkinen ${ }^{1}$, Ingolf Kühn ${ }^{4,5,6}$, Mikko Kuussaari ${ }^{1}$, Oliver Schweiger ${ }^{4}$, Anu Valtonen ${ }^{7}$, Peter M. van Bodegom ${ }^{8}$ and Markus Franzén ${ }^{4}$
${ }^{1}$ Finnish Environment Institute (Syke), Natural Environment Centre, PO Box 140, FI-00251 Helsinki, Finland, ${ }^{2}$ Departamento de Ecologia, Universidade de Brasília, Campus Universitário Darcy Ribeiro, Brasília - DF 70910-900, Brazil, ${ }^{3}$ Centre for Ecology, Evolution and Environmental Changes (CE3C), Faculdade de Ciencias da Universidade de Lisboa, 1749-016 Lisboa, Portugal, ${ }^{4}$ Helmholtz Centre for Environmental Research - UFZ, Department of Community Ecology, Theodor-LieserStrasse 4, D-06120 Halle, Germany, ${ }^{5}$ Martin-Luther University Halle-Wittenberg, Geobotany and Botanical Garden, Am Kirchtor 1, 06108 Halle, Germany, ${ }^{6}$ German Centre for Integrative Biodiversity Research (iDiv) Halle-Jena-Leipzig, Am Deutschen Platz 5e, 04103 Leipzig, Germany, ${ }^{7}$ Department of Environmental and Biological Sciences, University of Eastern Finland, PO Box 111, FI-80101 Joensuu, Finland, ${ }^{8}$ Institute of Environmental Sciences, Leiden University, Einsteinweg 2, Leiden, The Netherlands

${ }^{*}$ Correspondence: Juha Pöyry, Finnish Environment Institute (Syke), Natural Environment Centre, PO Box 140, FI-00251 Helsinki, Finland.

E-mail: juha.poyry@ymparisto.fi

\section{ABSTRACT}

Aim Nitrogen deposition is a major global driver of change in plant communities, but its impacts on higher trophic levels are insufficiently understood. Here, we introduce and test a novel conceptual trait-based model describing how the effects of soil eutrophication cascade to higher trophic levels across differential plant-herbivore interactions.

Location Northern Europe.

Methods We synthesize previous literature on the effects of nitrogen on plants and herbivorous insects as well as relevant multispecies patterns of insect communities concerning species dietary breadth, body size, dispersal propensity and voltinism in order to derive the model. We empirically evaluate the proposed, hitherto untested, four main model pathways using statistical modelling and data on 1064 northern European butterfly and moth species, their life-history traits, phylogeny and population trends.

Results We show that across all species: (1) larval dietary breadth and host plant foliar nitrogen content are positively and equally strongly related to insect body size, and that (2) multivoltinism, host plant preferences for soil nitrogen, body size and larval dietary breadth are positively related to population trends of butterflies and moths as predicted by the model. Positive relationships between plant foliar nitrogen content and body size as well as multivoltinism and population trends are the first multispecies demonstrations for these patterns.

Main conclusions Soil nitrogen enrichment amplifies the diverging trends of herbivorous insects feeding on nitrophilous versus nitrophobous plants through differential plant-herbivore interactions, causing predictable changes in community composition at higher trophic levels. A positive foliar nitrogeninsect body size relationship, now empirically supported, is the integrating link within this cascade. As nitrogen deposition is a global driver, our model suggests that a major future trend may be an increased dominance of insects that are large, dispersive, multivoltine, dietary generalists or specialized on nitrophilous plant species at the expense of species preferring oligotrophic environments.

\section{Keywords}

Butterflies, community change, conceptual model, eutrophication, host plants, insect herbivores, moths, nitrogen deposition, population trends, species traits. 


\section{INTRODUCTION}

Several studies have documented an ongoing transformation of natural communities across the world (Dornelas et al., 2014; Pimm et al., 2014), with herbivorous insects being one of the groups showing major changes in diversity (Biesmeijer et al., 2006; Carvalheiro et al., 2013). A number of large-scale drivers have been connected with these observed trends, including habitat loss, climatic change and invasive species (see Thomas et al., 2004; Winter et al., 2009; Pereira et al., 2010). In general, species with broad habitat requirements and strong dispersal abilities are expected to be better adapted to face the challenges caused by such globally acting drivers (Warren et al., 2001; Pöyry et al., 2009; Angert et al., 2011).

Another large-scale driver is nitrogen deposition, which affects many ecosystems across the world (Galloway et al., 2008; Dise et al., 2011). The resulting soil eutrophication induces widespread changes in plant community composition, benefitting plant species that are adapted to high soil nutrient levels (Ceulemans et al., 2013; Dirnböck et al., 2013). While such primary trophic level changes are well documented (Bobbink et al., 2010), impacts on higher trophic levels, for example herbivorous insects, are less well understood (but see Throop \& Lerdau, 2004; WallisDeVries, 2014). In addition to inducing changes in plant community composition, soil nutrient enrichment may selectively affect population trends of herbivorous insects through dietary nitrogen availability (Awmack \& Leather, 2002) and through changes in vegetation structure. Nutrient enrichment increases plant growth rates, causing microclimatic cooling that may limit niche availability of insect species inhabiting warm habitat patches (WallisDeVries \& van Swaay, 2006).

A number of large-scale correlative patterns among the traits of insect species have been reported. These include positive relationships between dietary breadth and insect size (e.g. Lindström et al., 1994; Davis et al., 2013), insect size and dispersal ability (e.g. Nieminen et al., 1999; Sekar, 2012; Stevens et al., 2012) and between dispersal ability and the recent population trends of insects (Warren et al., 2001; Pöyry et al., 2009). However, it is insufficiently known how these relationships are affected by eutrophication and how the responses of herbivorous insects to eutrophication are modified by species traits. Moreover, it is possible that eutrophication is further linked with species abilities to produce multiple generations per season, but this has so far only been sporadically studied (WallisDeVries, 2014). To fill these gaps, we propose here a novel conceptual trait-based model. This model provides a framework to explore how soil eutrophication affects the observed opposing trends of herbivorous insects feeding on either 'nitrophilous' or 'nitrophobous' host plants, i.e. plant species that are adapted to high and low nitrogen levels, respectively (Fig. 1). To achieve this, we combine known multispecies relationships with a novel integral link: the positive plant foliar nitrogen-insect size relationship. We argue that the relationships discussed above are modified by soil eutrophication, resulting in cascading impacts that strengthen the population trends of herbivorous insects. We evaluate the model using correlative statistical modelling and reinforce the appropriateness of our model predictions through a comprehensive empirical study of the multiple causal links within one study system, northern European Lepidoptera, i.e. butterflies and moths.

\section{Description of the conceptual trait-based model}

The model is based on the confirmed impacts of soil eutrophication by nitrogen deposition on the nitrogen content of individual plants and on plant community composition and vegetation structure (Fig. 1). Individual plants growing in eutrophic soils have been shown to contain higher concentrations of nitrogen than conspecific individuals growing in oligotrophic soils (arrow 1 in Fig. 1; Pitcairn et al., 2003; Fujita et al., 2013). Community-level impacts of nitrogen enrichment on plants include decreasing population trends of nitrophobous plant species as well as increased height and dominance of vegetation by nitrophilous plant species (arrows 2a and 2b in Fig. 1; Ceulemans et al., 2013; Dirnböck et al., 2013).

Several studies, focusing mostly on single species, have shown that availability of dietary nitrogen is positively correlated with growth rate and individual body size in insects (for reviews see Mattson, 1980; White, 1993; Awmack \& Leather, 2002; Throop \& Lerdau, 2004). The importance of foliar nitrogen content for insect herbivores may be explained by the stoichiometric theory of element availability. This theory postulates a strong asymmetry in nitrogen content between plants (low content) and their herbivores (high content) (Elser et al., 2000; Fagan et al., 2002), due to which foliar nitrogen content is a limiting factor for the growth of insect herbivores (Mattson, 1980; Fagan et al., 2002). Consequently, variation in nitrogen content among individual host plants is likely to result in a positive within-species relationship between the nitrogen content of host plants and the body size of insect herbivores. We extend this relationship to the between-species level and hypothesize that insect species adapted to feed on plants with a high nitrogen content should be larger than insects feeding on plants with a low nitrogen content (arrow 3 in Fig. 1). An important additional link is that the increased growth rate emerging from a higher availability of dietary nitrogen, may also increase the incidence of multivoltinism, i.e. the occurrence of more than one generation during a summer season (arrow 4 in Fig. 1) (WallisDeVries, 2014).

The prediction that insect species feeding on nitrogen-rich host plant species will have a larger body size is combined with the observation of increasing population trends of nitrophilous plant species (arrow 2a in Fig. 1). Given the increasing proportion of nitrophilous species in plant communities, we can also expect that larger insect species will become increasingly dominant in communities of herbivorous insects in response to soil nitrogen enrichment (arrow 5 in Fig. 1). As the next part of the model we assume a positive relationship between dietary breadth and insect body size 


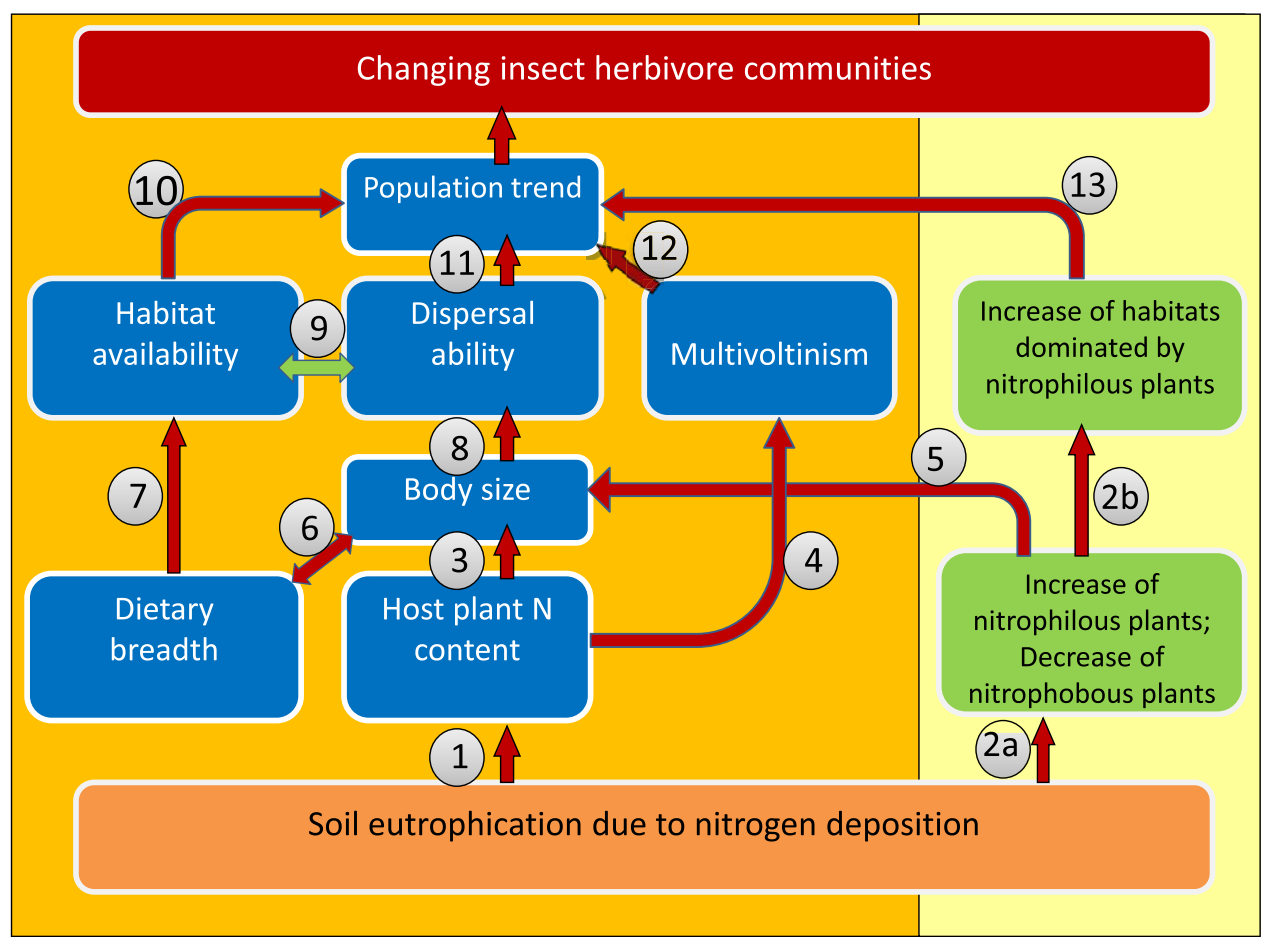

Figure 1 A conceptual model describing how the impacts of nitrogen deposition are mediated through changes in host plant nitrogen content, insect body size and vegetation composition and structure, strengthening the observed opposing population changes of herbivorous insects according to the nitrogen preferences of their larval host plant species. Factors connected with traits of insect herbivores are marked with rectangles on the left and centre, and factors describing vegetation composition and structure are marked with rectangles on the right. All other arrows indicate positive relationships whereas the arrow 9 indicates a nonlinear relationship. Directions of the relationships in the model are combined from previous empirical studies and observations of the current study. Key: 1, increasing foliar nitrogen due to soil eutrophication; $2 \mathrm{a}, 2 \mathrm{~b}$, increasing dominance of nitrophilous plant species in ecosystems; 3 , insect body size is positively related to foliar nitrogen; 4, increased foliar nitrogen increases development rate and likelihood of multivoltinism; 5 , insect species with large body size increase in abundance; 6 , insect body size is positively related to dietary breadth; 7 , dietary breadth is positively related to habitat availability; 8 , insect body size is positively related to dispersal ability; 9 , habitat availability and dispersal ability are interrelated; 10, habitat availability and trends of insect species are positively related; 11, dispersal ability and trends of insect species are positively related; 12 , multivoltine species show positive and univoltine species negative population trends; 13 , insects feeding on nitrophilous plants species show positive and insects feeding on nitrophobous plants show negative population trends. For details of the model see 'Description of the conceptual model'.

(arrow 6 in Fig. 1), a pattern empirically shown for many insect groups (e.g. Lindström et al., 1994; Davis et al., 2013). An obvious outcome of a wider dietary niche is increased probability of finding host plants needed for larval development. Thus species with broad dietary niches are expected to have more suitable habitats available in the landscape than species with narrower niches (arrow 7 in Fig. 1; e.g. Dennis et al., 2005). Moreover, previous empirical studies have shown that the size of butterflies and moths is positively related to their dispersal ability (arrow 8 in Fig. 1; Nieminen et al., 1999; Sekar, 2012; Stevens et al., 2012; Slade et al., 2013). Therefore, larger species will not only have more suitable habitats but are also able to locate them with an increased probability and over longer distances due to their higher dispersal ability.

Dispersal ability may also be linked to habitat availability, but this relationship is more complex than the previous ones (arrow 9 in Fig. 1). Models of the evolution of dispersal in fragmented landscapes have produced conflicting predictions about the impact of habitat availability on dispersal ability (e.g. Hanski, 2011). Similarly, empirical support has been presented for both decreasing (Schtickzelle et al., 2006) and increasing (Duplouy et al., 2013) dispersal propensity in response to habitat loss. However, it has recently been proposed that these empirical examples represent different parts of the habitat availability gradient so that the relationship between dispersal and habitat availability would be nonlinear, reaching a minimum at some 'intermediate' level of habitat availability (Hanski, 2011).

Previous studies on population changes of butterflies and moths have shown that generalist species with broad habitat requirements (arrow 10 in Fig. 1) and strong dispersal ability (arrow 11 in Fig. 1) show increasing population trends and range expansions, whereas specialist species with strict habitat requirements and poor dispersal ability show negative trends and range contractions in response to environmental changes 
(Warren et al., 2001; Pöyry et al., 2009; Angert et al., 2011). It has also been suggested that an increased propensity to multivoltinism may be linked to positive population trends (arrow 12 in Fig. 1; WallisDeVries, 2014). Finally, recent studies have documented positive trends for insect species feeding on nitrophilous plant species and negative trends for insects feeding on nitrophobous plant species (arrow 13 in Fig. 1; Öckinger et al., 2006; Betzholtz et al., 2013; Hendriks et al., 2013).

To summarize, various links of the model, with the novel foliar nitrogen-insect body size relationship at an integral position, mediate the cascading impacts of nitrogen deposition and soil eutrophication and ultimately reinforce the diverging trends of insect herbivores according to the foliar nitrogen content and soil nitrogen preferences of their host plants. Communities of herbivorous insects are thus predicted to become increasingly dominated by species that are large, dispersive, multivoltine, dietary generalists or specialized on nitrophilous plant species, and these traits are expected to co-occur.

\section{Empirical test of the model}

We empirically evaluate our model using statistical modelling methods and northern European butterflies and moths as the focal group. Firstly, we test whether the body size of butterflies and moths is related to larval dietary breadth (arrow 6 in Fig. 1) and foliar nitrogen content of the larval host plant (arrow 3 in Fig. 1), and assess the relative importance of these variables. Secondly, we test whether the foliar nitrogen content of the larval host plants of butterflies and moths is related to their type of voltinism. Thirdly, we test whether the recent (1993-2012) population trends of butterflies and moths are related to the four main pathways outlined in the conceptual model: (1) dietary breadth of their use of host plants, reflecting habitat availability (arrows 7 and 10 in Fig. 1); (2) body size, partly mediating the impact of foliar nitrogen content of the host plant and reflecting dispersal ability (arrows 8 and 11 in Fig. 1); (3) voltinism, partly mediating the impact of foliar nitrogen content of the host plant and reflecting individual growth rate (arrows 4 and 12 in Fig. 1); and (4) the mean Ellenberg nitrogen $(\mathrm{N})$ indicator value of host plants as an integrated measure reflecting prevailing soil fertility conditions and plant nitrogen preferences (cf. Fujita et al., 2013), including the impacts of soil eutrophication thereon (arrows $2 \mathrm{~b}$ and 13 in Fig. 1). We also use Ellenberg $\mathrm{N}$ indicator values as a proxy for foliar nitrogen content, and thus the variance explained by this variable is divided between the two different pathways (arrows 1 and 2a) in the model.

\section{METHODS}

\section{Selection of study species}

In this study we use a unique dataset of 1064 butterfly and moth species, occurring either as residents or regular migrants in northern Europe (in Sweden and Finland), that feed on vascular plants during the larval stage. Species feeding on lichens, mosses and dead plant material were excluded. For each species we gathered information on adult sizes, host plant Ellenberg $\mathrm{N}$ indicator values, voltinism and dietary breadth. The selected species are placed in 23 families and 11 superfamilies according to current Lepidopteran systematics (Fig. S1 in Appendix S1 in the Supporting Information). We chose to focus on butterflies and moths because they are well known compared with most other groups of herbivorous insects, and reliable data exist on their lifehistory characteristics and population trends.

\section{Butterfly and moth species and their host plant use}

We first gathered information on larval host plant use published in the northern European literature on butterflies and moths (Appendix S2). Based on this information and the Ellenberg $\mathrm{N}$ indicator values, describing the soil fertility conditions and nitrogen preferences of larval host plants (Ellenberg et al., 1991; Schaffers \& Sykora, 2000; Fujita et al., 2013), we calculated an average Ellenberg $\mathrm{N}$ indicator value of host plants used by each butterfly and moth species (see Table S1 in Appendix S2 for representative species examples). Previous studies have demonstrated that Ellenberg $\mathrm{N}$ indicator values are correlated with plant foliar nitrogen content, thus providing a proxy of host plant nitrogen availability for herbivorous insects (Duru et al., 2010; Hodgson et al., 2011). To validate this relationship in our set of larval host plant species, we prepared a list of all plant species used as hosts $(n=1239)$, and accessed the TRY plant trait database for data on plant foliar nitrogen content calculated per dry weight (Kattge et al., 2011; Yguel et al., 2011). This information was available for $30 \%$ of the species included in our study $(n=375)$, and for this subset of species we calculated the Pearson correlation between the Ellenberg $\mathrm{N}$ indicator values and foliar nitrogen content and found a statistically significant (although rather weak) positive correlation $(r=0.25, P<0.001$; Fig. S15 in Appendix S2).

Secondly, butterfly and moth species were classified into three groups according to their dietary breadth: (1) monophagous species which feed strictly on one plant species in the study region $(n=145)$, (2) oligophagous species which feed on fewer than six (two to five) plant species or are restricted to a single plant genus $(n=416)$, and (3) polyphagous species which feed on several (six or more) plant species or genera $(n=503)$ (see Appendix S2).

Thirdly, butterfly and moth species were classified into four groups according to their developmental rate and type of voltinism: (1) semi-voltine, i.e. species whose development time is 2 years or longer $(n=42)$, (2) univoltine, i.e. species that exclusively have one generation per year $(n=594)$, (3) facultatively bivoltine, i.e. species that can produce a partial second generation predominantly during warm summers $(n=149)$, and (4) multivoltine, i.e. species regularly producing at least two generations per year $(n=47)$. Classification 
of voltinism was based on flight period observations in the same atlas data that were used to derive the population trends (Finnish Museum of Natural History, 2013; see below).

Finally, information on the average body size (measured as wing span in $\mathrm{mm}$ ) of males reported for each butterfly and moth species was extracted from the same sources (Appendix S2). Males were chosen because size estimates of males were available for all species and comparable size estimates would have been difficult to obtain for species with wingless females.

\section{Calculation of butterfly and moth population trends}

We used distribution atlas data on Finnish butterflies and moths gathered by voluntary observers (Finnish Museum of Natural History, 2013) to calculate recent population trends for individual species. We focused on observations made during the most recent 20-year period (1993-2012), because nitrogen deposition has remained above the critical load in many parts of Finland during this period (Nordin et al., 2005; Ruoho-Airola et al., 2014) with reported large-scale impacts on vegetation (Dirnböck et al., 2013). From the total of 1064 species, we were able to extract population trend data for those 832 species that had a minimum of 50 observations in the database during the 20 -year period. The population trend data were based on c. 1.46 million observations of one or more individuals. In order to account for the annually varying observational efficiency (variation in the total number observations from c. 26,300 in 1996 to $c$. 118,500 in 2012), for each of the 832 species, we calculated an annual index of relative commonness by dividing the annual number of observations of that species by the annual total number of observations of all species. To make the species-specific annual indices of relative commonness independent of absolute numbers of observations, and thus comparable among the species, we let them vary from zero to one by dividing the annual index values by the maximum values observed during the 20 -year period. Finally, we fitted linear regressions between the annual index values and observation year for each species. The resulting coefficient estimates of the regression slopes were then considered as estimates of the population trends and their standard errors (SE) were used as a measure of their uncertainty.

Although the annual index values varied from 0 to 1 , we chose to use linear regression instead of binomial regression for the following reasons: (1) binomial regression would not allow lower or higher values of the abundance index than those observed in our data for the years 1996-2012 to be predicted, which is an illogical restriction for species showing a constantly increasing range expansion trend; (2) the coefficient estimates of the regression slopes for the species are highly similar $(r=0.929)$ between binomial and linear regression; and (3) applying binomial regression would result in a smaller species sample (623 instead of 832) and a clear loss in statistical power.
The applied methodology of deriving annual indices for the studied species resembles methods that are frequently used to analyse population changes based on atlas data (see, e.g., Warren et al., 2001; Thomas et al., 2004). In such studies changes in the number of observations of a species are compared between two or more time periods, and possible variation in observational activity is typically controlled for by, for example, resampling or relating observations of a species to total observations (see Botts et al., 2012). The main difference between our work and these earlier studies is in the temporal resolution, i.e. we focused on a possible trend in annual observations during a 20 -year period, whereas previous studies focused on changes between two or more distinct periods.

\section{Statistical analyses}

We performed three different sets of analyses with our data. We first evaluated if dietary breadth (treated as an ordered factor), the Ellenberg $\mathrm{N}$ indicator value of larval host plants and their interaction term were related to the body size of butterfly and moth species. Secondly, we tested if the mean Ellenberg $\mathrm{N}$ indicator value of larval host plants was related to the type of voltinism of butterflies and moths. In the third set of analyses, dietary breadth, mean Ellenberg $\mathrm{N}$ indicator value of larval host plants, voltinism, body size of butterflies and moths and their interaction terms were related to the recent population trends of butterfly and moths species. Here, a covariate (1/SE of the regression slope) was entered prior to explanatory variables to control for the reliability of the trend.

To disentangle which combinations of explanatory variables show the most parsimonious fit to the data and to explore the overall relative importance of explanatory variables, we applied the approach of multimodel inference (Burnham \& Anderson, 2002), except in the second analysis which included just one explanatory variable. Thus, in the first set of analyses we fitted four models including all possible combinations of the two explanatory variables and their interaction term. In the third set of analyses, we fitted 66 models including all possible combinations of the four explanatory variables and their two-way interaction terms. The relative importance of each explanatory term was calculated by summing the weights of the quasi-likelihood information criterion (QIC; Pan, 2001) across those models where the respective term was present (Johnson \& Omland, 2004). We used model averaging to calculate the parameter estimates with their confidence intervals for the second set of analyses focusing on population trends, where none of the models were outstandingly supported by the data (QIC weight of the best model $<0.9$; Johnson \& Omland, 2004).

To account for potentially confounding effects of phylogenetic relatedness among the study species, we derived a phylogenetic hypothesis for the 1064 focal species (see Appendix S1) and included this information in the two sets of analyses by fitting generalized estimation equations (GEE) using the 
ape library, version 3.0.11 (Paradis, 2006) within the R statistical environment ( $\mathrm{R}$ Core Team, 2013). As the response variables were normally distributed, we used a 'Gaussian' error structure and identity link functions in all models. Values of the four main explanatory variables, body size (wing span), mean Ellenberg $\mathrm{N}$ indicator values of larval host plants, dietary breadth and voltinism, were significantly affected by phylogenetic relatedness among species as indicated by Moran's I autocorrelation indices (Paradis, 2006). The observed and expected Moran's $I$ values with accompanying significances were as follows: dietary breadth (observed 0.166, expected $-0.001, \quad P<0.001$ ), voltinism (observed 0.125, expected $-0.001, P<0.001)$, mean Ellenberg $\mathrm{N}$ indicator values (observed 0.070 , expected $-0.001, P<0.001$ ) and body size (observed 0.384, expected $-0.001, P<0.001$ ). This indicates that the use of phylogenetically corrected regression models is warranted.

\section{RESULTS}

\section{Body size of butterflies and moths}

The variation in body size of butterflies and moths was strongly related to dietary breadth and the mean nitrogen preferences of larval host plants, as indicated by their Ellenberg $\mathrm{N}$ values (QIC weight $=0.998$; Table 1, Fig. 2). This suggests that body size of butterflies and moths increases with increasing dietary breadth and when feeding on nitrogen-rich plants associated with eutrophic environments (Table 1, Fig. 2). The interaction between dietary

Table 1 Results of multimodel inference for the body size of butterflies and moths, with different combinations of dietary breadth, mean host plant Ellenberg $\mathrm{N}$ indicator value and their interaction term as explanatory variables.

\begin{tabular}{lllllll}
\hline Dietary breadth & Ellenberg N value & Dietary breadth $\times$ Ellenberg N value & QIC & $\Delta$ QIC & Likelihood & QIC weight $\left(w_{i}\right)$ \\
\hline $\mathbf{1 . 3 8 1} \pm \mathbf{0 . 0 6 0}$ & $\mathbf{0 . 4 6 1 \pm 0 . 0 1 6}$ & & $\mathbf{1 5 8} \mathbf{9 8 9 . 1}$ & $\mathbf{0 . 0}$ & $\mathbf{1 . 0 0 0 0}$ & $\mathbf{0 . 9 9 9 8}$ \\
$1.177 \pm 0.151$ & $0.450 \pm 0.120$ & $0.042 \pm 0.030$ & 159006.2 & 17.1 & 0.0002 & 0.0002 \\
$1.494 \pm 0.016$ & & & 161670.1 & 2681.0 & 0.0000 & 0.0000 \\
& $0.495 \pm 0.016$ & 0 & 161925.8 & 2936.7 & 0.0000 & 0.0000 \\
\hline 1.000 & 1.000 & 0 & Sum of QIC weights & \\
\hline
\end{tabular}

QIC, quasi-likelihood information criterion.

The model with the overwhelming likelihood of being the best model for the observed data according to QIC weight $\left(w_{i}\right)$ is marked in bold. Coefficient values with standard errors are given for all model terms.
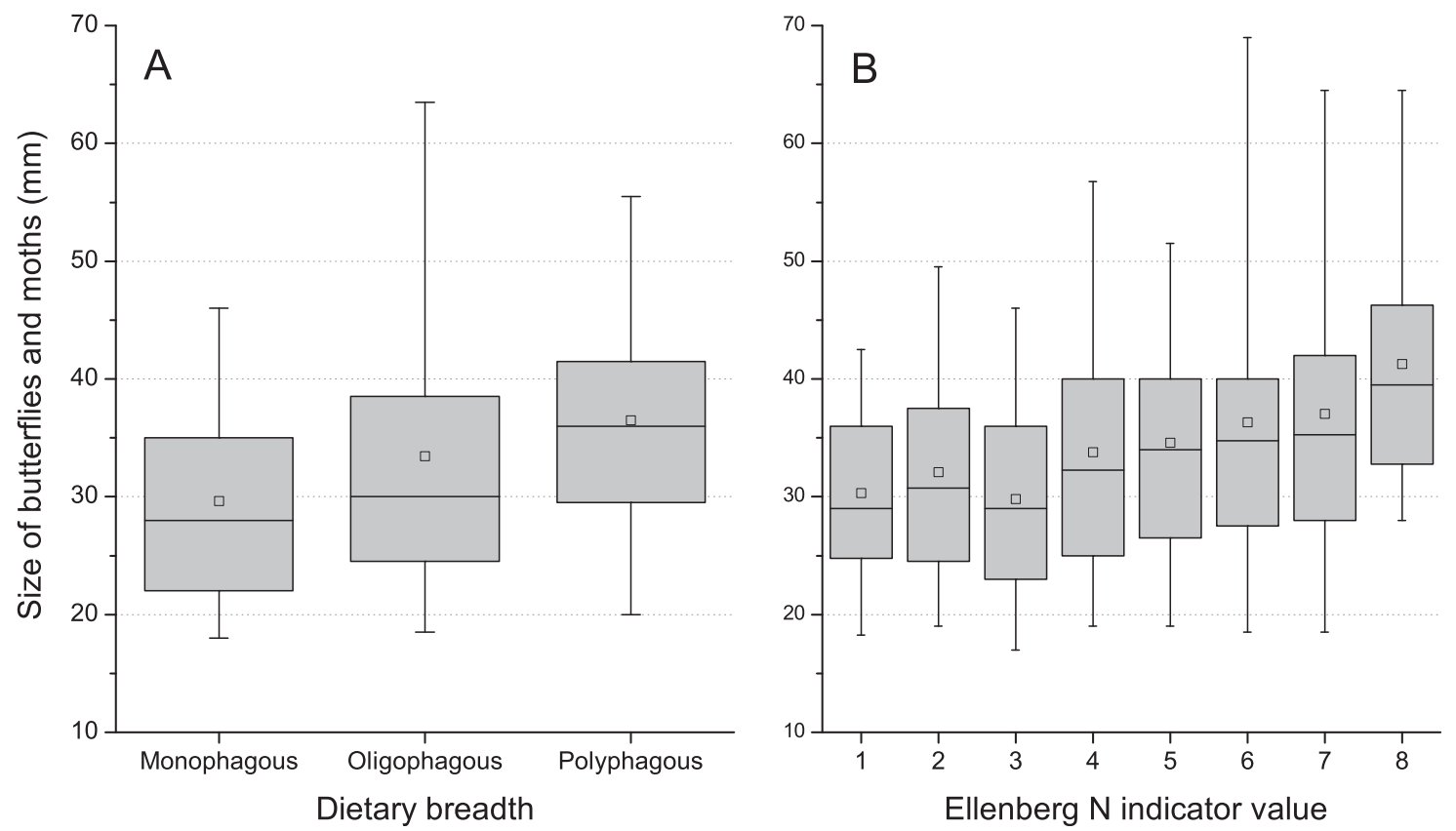

Figure 2 Variation of butterfly and moth sizes (a) across the classes of dietary breadth (in increasing order monophagous, oligophagous and polyphagous) and (b) in relation to the Ellenberg nitrogen $(\mathrm{N})$ indicator values of larval host plants. The boxes represent $25 \%$ and $75 \%$ percentiles and medians of the data, and error bars represent $5 \%$ and $95 \%$ percentiles. Small quadrats within the boxes represent mean values. Note that the figure is based on the original values where phylogenetic relatedness is not accounted for. 
breadth and host plant nitrogen preferences did not improve the model fit in addition to the main effects (Table 1).

\section{Foliar nitrogen content and voltinism}

We observed a positive relationship between the mean Ellenberg $\mathrm{N}$ values of larval host plants and voltinism type ( $F=522.49$, d.f. $=1, P<0.001)$, so that the number of generations per season increased with the foliar nitrogen content. This result indicates a positive impact of dietary nitrogen availability on growth rates.

\section{Population trends of butterflies and moths}

None of the fitted models on the recent population trends of butterflies and moths was distinctly the best, with QIC weights of the six top models varying between 0.06 and 0.11 (Table 2). According to the sums of QIC weights, voltinism of butterfly and moth species showed the highest relative importance (0.93), followed closely by mean nitrogen preferences of larval host plants (0.87), dietary breadth (0.59) and body size of butterflies and moths (0.48). All these four explanatory variables were positively related to the observed trends of butterflies and moths (Table 2, Fig. 3). The two-way interaction between voltinism and Ellenberg $\mathrm{N}$ indicator value showed a moderately high contribution according to QIC weights (0.50) (Fig. S16 in Appendix S4). The other interactions produced only modest improvements to the model fit (sum of QIC weights in all cases $<0.16$ ), although a negative coefficient of the diet breadth-Ellenberg $\mathrm{N}$ indicator value interaction suggests a stronger impact of nitrogen preferences on trends in butterflies and moths with a more specialized diet (Table 2, Fig. S17 in Appendix S4). The impacts of each of the four main effects were maintained even after accounting for the other three variables, respectively (Appendix S4 Fig. S18).

\section{DISCUSSION}

In this paper we present a novel trait-based conceptual model that combines several simultaneously acting mechanisms and explains how their cascading impacts can produce opposite population trends of insect herbivores feeding on plants with different nitrogen preferences and corresponding foliar nitrogen contents. The conceptual model, which might also be classified as a phenomenological model, was tested here by using empirical statistical methods to verify whether the included processes are likely to cause the observed patterns (see Guisan \& Zimmermann, 2000 for a discussion on the classification of ecological models and statistical testing of them). According to this model, population trends of herbivorous insects are affected via four separate pathways, mediated firstly via habitat availability, secondly via dispersal ability of insect species, thirdly via development rate and voltinism, and fourthly via vegetation changes. All four pathways are affected by soil nitrogen enrichment.

By using a large dataset of butterfly and moth traits, population trends and statistical modelling methods where phylogenetic relatedness is accounted for, we found empirical support for six relationships included in the model. Firstly, we showed that herbivorous insect species, here exemplified by butterflies and moths in northern Europe, are larger when: (1) they have a wide dietary breadth and (2) they utilize larval host plants preferring nitrogen-rich soils and with a corresponding higher foliar nitrogen content, the latter being to our knowledge the first statistically well-supported comparative multispecies report of this pattern. Secondly, we showed that butterflies and moths were more likely to show positive population trends when they have: (1) multiple generations during a summer season, reflecting increased development rate, (2) higher larval host plant nitrogen requirements, reflecting the independent impact of soil nitrogen enrichment on vegetation, (3) large body size, mediating the positive impact of foliar nitrogen content on size, and reflecting a higher dispersal ability and probability of finding suitable breeding habitats, and (4) wide dietary breadth, reflecting higher habitat availability. When combined with previous studies covering the other seven relationships included in the model, our findings provide empirical support for all interactions in the model. The positive foliar nitrogen-insect body size relationship represents a novel integrating link that mediates the impact of nitrogen addition via two of the proposed pathways. An important next step in verifying the generality of the model is to gather empirical data on connections included in the model within other study systems, and to evaluate the strength of the connections found in other herbaceous insect food webs. Such future steps could also pave the way for developing the conceptual model presented by us towards a mechanistic model.

We concentrated on bottom-up effects when deriving the model. The main reason for this decision is that we expect top-down impacts to be less important under most situations because interspecific competition among insect herbivores is seldom so strong that it could modify community structure (Kaplan \& Denno, 2007) and density-dependent regulation of herbivore insect populations by their natural enemies appears rather rare (e.g. Stiling, 1987).

As we lacked detailed data on habitat availability and dispersal ability for a large proportion of the focal butterfly and moth species, we used dietary breadth (Dennis et al., 2005) and butterfly and moth body size (Nieminen et al., 1999; Sekar, 2012; Stevens et al., 2012; Slade et al., 2013), respectively, to test the importance of these variables indirectly. The impact of the third explanatory variable, nitrogen preference of larval host plants, as represented by the mean Ellenberg $\mathrm{N}$ indicator values (Ellenberg et al., 1991; Schaffers \& Sykora, 2000; Fujita et al., 2013), was divided between two pathways, firstly via foliar nitrogen content affecting body size and secondly via the independent effect of soil nitrogen enrichment on vegetation. The positive relationship we documented between Ellenberg $\mathrm{N}$ indicator values and the foliar nitrogen content of plant species was weak, though statistically significant and in line with previous observations of this pattern (Duru et al., 2010; Hodgson et al., 2011). The relative weakness of the relationship may be explained by the fact that measurements were collected from a large number of field 


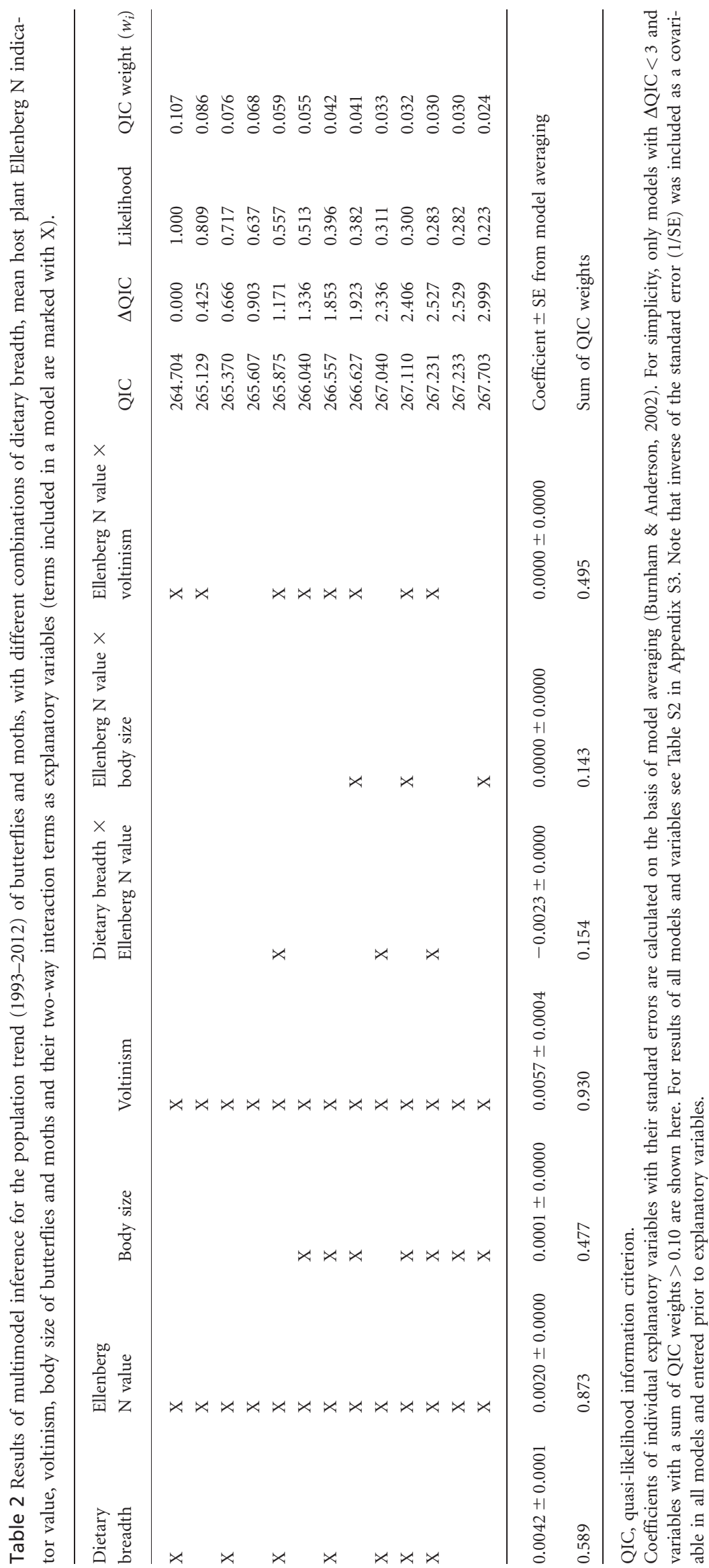



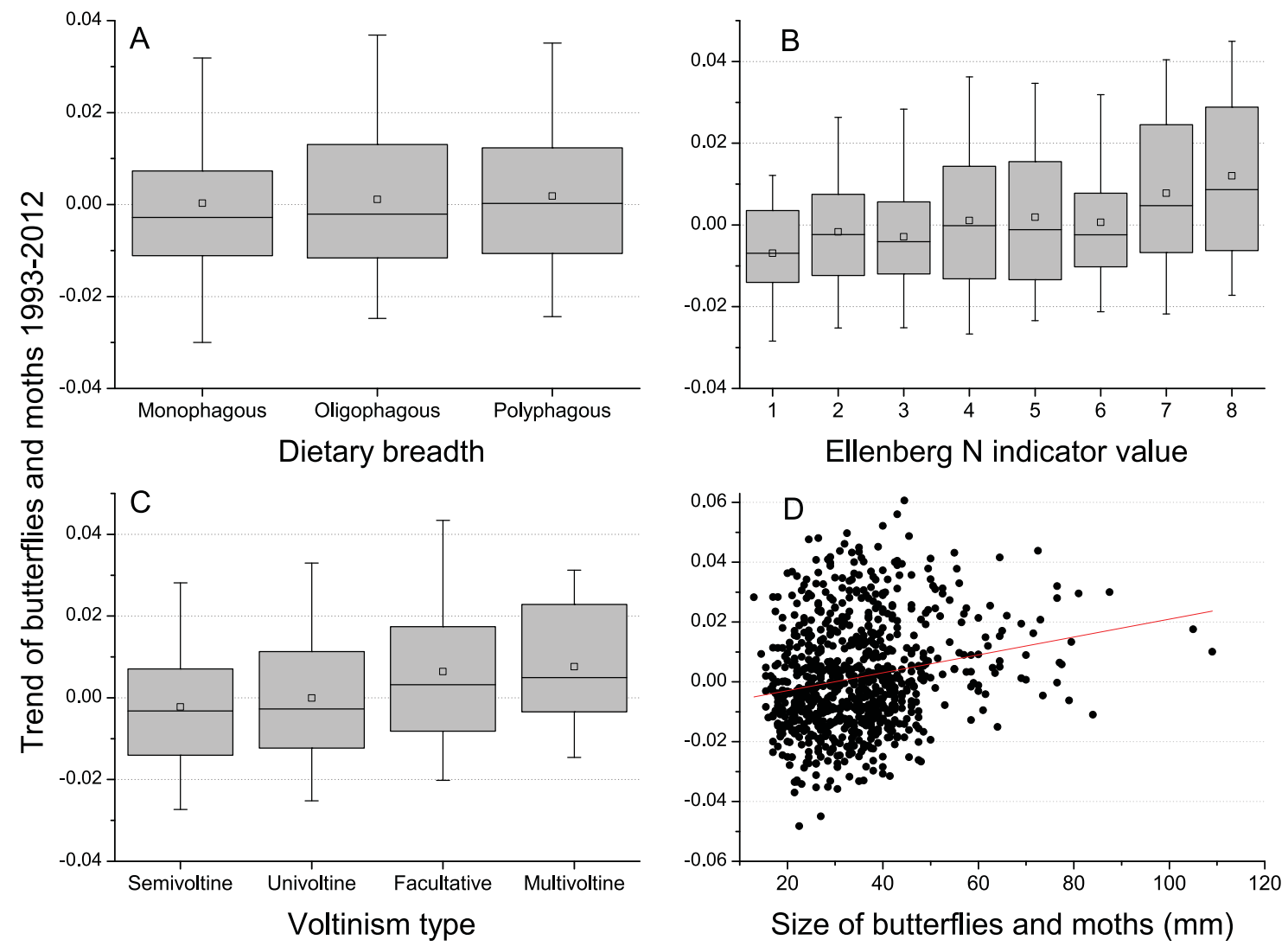

Figure 3 Population trends of butterfly and moth species in Finland (1993-2012) in relation to (a) dietary breadth of the species (in increasing order monophagous, oligophagous and polyphagous), (b) the Ellenberg nitrogen $(\mathrm{N})$ indicator values of larval host plants, (c) voltinism type of the species, and (d) the size of butterfly and moths species. The boxes represent $25 \%$ and $75 \%$ percentiles and medians of the data, and error bars represent $5 \%$ and $95 \%$ percentiles. Small quadrats within the boxes represent mean values. The straight line in (d) shows fit of the linear regression model. Note that the figure is based on the original values where phylogenetic relatedness is not accounted for.

studies with highly variable soil nutritional status and plants species are plastic in their foliar nitrogen response (cf. Kattge et al., 2011).

The novel observation of a positive relationship between nitrogen content of host plants and the size of herbivorous insect species is in line with predictions derived from the stoichiometric theory: insects feeding on plants with a high nitrogen content should on average be larger than insect species feeding on plants with a low nitrogen content (Elser et al., 2000; Fagan et al., 2002). On the other hand, when occurring in excessive amounts, the impacts of nitrogen on insect growth and fecundity might turn negative (e.g. Tao et al., 2014). However, as the majority of empirical studies documented a positive relationship between dietary nitrogen availability and insect size within individual species (Mattson, 1980; White, 1993; Awmack \& Leather, 2002; Throop \& Lerdau, 2004), and as our comparative analysis documented this relationship at the between-species level, the negative impacts of excessive nitrogen on insect growth do not seem to be dominant under natural circumstances.

A number of previous studies have shown that dietary breadth is positively related to insect body size (e.g.
Lindström et al., 1994; Davis et al., 2013). The underlying reasons are still uncertain, but it has been suggested that polyphagous species experience higher physiological stress due to plant secondary compounds used in their quantitative defence against herbivores and larger size may buffer against their deleterious effects (Lindström et al., 1994). Smaller species have lower requirements for energy and plant material during their development, and thus they are adapted to feeding on herbs. Herbs, by contrast, often use toxic chemicals (e.g. alkaloids) as a qualitative defence against herbivores and it is likely that this increases the probability of specialization among small herbivorous insects (Davis et al., 2013). The results of our comparative analysis are in line with these earlier observations, but they go a step further and show that foliar nitrogen content is as important as host plant dietary breadth for explaining the variation in body size of butterflies and moths. The suggested explanations for a positive dietary breadth-body size relationship do not exclude either direction of causality in our model (Arrow 6 in Fig. 1).

Our results also indicate that population trends of butterflies and moths were strongly related to voltinism, followed by nitrogen preferences of larval host plants, dietary breadth 
and body size. This result suggests that a high developmental rate and propensity to produce multiple generations during a favourable season is the most important factor for recent population trends of butterflies and moths in northern Europe, followed by the impact of soil nitrogen enrichment on vegetation composition and structure, species dispersal ability and habitat availability. Inspection of partial residual plots supported these results for all four variables.

According to our results, voltinism showed the highest independent contribution to population trends of butterflies and moths. This means that populations of species with a propensity to produce multiple generations during a summer season were most likely to increase. This may be understood in the light of two factors. Increased foliar nitrogen content increases larval development rate (Mattson, 1980; White, 1993; Awmack \& Leather, 2002; WallisDeVries, 2014) and recent climatic warming increases the likelihood of producing multiple generations (Altermatt, 2010; Pöyry et al., 2011), two separate global drivers that potentially have combined impacts. Previous studies have documented an increase in the occurrence of multivoltinism among lepidopteran species (Altermatt, 2010; Pöyry et al., 2011), and multivoltinism has been suggested as one species trait that contributes to positive population trends of butterflies in response to nitrogen deposition (WallisDeVries, 2014); however, to our knowledge conclusive empirical support for this has hitherto been lacking.

Previous studies on population changes of butterflies and moths in response to environmental change have documented that generalist species with broad habitat requirements and strong dispersal ability show increasing population trends and range expansions, whereas specialist species with strict habitat requirements and poor dispersal ability show negative trends and range contractions (Warren et al., 2001; Pöyry et al., 2009). The positive population trends in large and dietary generalist species found in our study confirm the often presented views that habitat availability and species dispersal ability are important determinants of species responses to global change (Thomas et al., 2004; Pereira et al., 2010). A number of previous studies have documented the positive relationship between body size and dispersal ability in butterflies (Sekar, 2012; Stevens et al., 2012). This issue is less well studied in moths, but the existing evidence suggests that a similar pattern also occurs across moth families (Nieminen et al., 1999; Slade et al., 2013).

Our observation of the positive relationship between nitrogen preferences of larval host plants and population trends of insect herbivores additionally highlights the cascading impact of soil fertility on insect herbivores through vegetation composition and structure. Interestingly, the effects of host plant nitrogen preferences depended on the level of herbivore dietary breadth, i.e. dietary specialists showed a stronger relationship between population trends and host plant nitrogen preferences than generalists. This can be understood against the background that insect species with a wide dietary breadth are likely to be less sensitive to changes in plant species composition, while dietary specialists follow population trends of their host plants more closely. Thus, insect species feeding on nitrophobous plants decline and insect species feeding on nitrophilous plants increase in abundance. While the impact of nitrogen deposition is known to be more pronounced for specialist than generalist plant species (Dise et al., 2011; Ceulemans et al., 2013), this is one of the few examples of herbivorous insects where global change selectively increases the abundance of specialist species (Betzholtz et al., 2013).

Eutrophication is not only an issue for arable fields, but its effects extend across all biotopes at a global scale (Galloway et al., 2008; Dise et al., 2011). During the last 20 years, nitrogen deposition in our focal study area in northern Europe has generally remained above or close to the critical load, defined as a threshold of pollutant exposure above which harmful impacts on the environment may occur (Nordin et al., 2005; Dise et al., 2011), despite the recent slight decrease (Ruoho-Airola et al., 2014). In addition to the reported large-scale changes in vegetation (Dirnböck et al., 2013), our conceptual trait-based model and empirical observations now indicate that heavy nitrogen deposition can ultimately impact region-wide and long-term population trends of herbivorous insects. Such impacts may be expected to be even more pronounced in many densely populated areas across the world, where exceedance of the critical load is notably higher than in northern Europe (Dise et al., 2011). The multiple and often interacting pathways of how soil eutrophication can impact higher trophic levels are complex. Generally, however, we show that eutrophication and a corresponding increase of nitrophilous plants (Ceulemans et al., 2013; Dirnböck et al., 2013) lead to herbivore communities dominated by species which are multivoltine, larger in size, stronger dispersers and have either a wider dietary - and consequently habitat - breadth or are specialized on nitrophilous plants.

It is also noteworthy that these traits constitute a 'trait syndrome' expected to be shared by species showing positive responses to other global drivers such as climate change (Warren et al., 2001; Pöyry et al., 2009; WallisDeVries, 2014). For example, a warming climate may affect the body size and wing span of insects. In northern populations, where a low thermal sum and time available for larval growth are limiting factors (Nylin \& Svärd, 1991), warming may induce an increase in body size and thus mobility. By contrast, increasing heat stress due to a warming climate may decrease body size in cold-adapted insect species, as has been documented in some butterflies of the high arctic (Bowden et al., 2015). Thus, contrasting responses in body size and mobility may occur depending on species identity. Climatic warming may also interact with soil nutrient availability. In moderately nutrient-limited systems, warming may further accelerate the increasing dominance of vegetation by nitrophilous species (e.g. Fridley et al., 2016). However, in severely nutrientlimited systems - where microbial nitrogen immobilization may increase - or water-limited systems no such effect is expected. To summarize, while warming and other global drivers partly lead to similar trait responses, the unique trait 
responses found here suggest a predominant direct impact of soil nitrogen enrichment.

With our model, we provide an overarching framework to integrate case studies of changes in insect communities linked to soil nitrogen enrichment. These include increased extinction probability of butterflies using host plants with low nitrogen preferences (Öckinger et al., 2006), range expansions of butterflies and moths using host plants with high nitrogen preferences (Betzholtz et al., 2013) and constrained increase of species richness in Orthoptera in areas with higher soil nitrogen enrichment (Hendriks et al., 2013). Our model might also be expanded to understand the recently observed homogenization of natural communities elsewhere (e.g. Carvalheiro et al., 2013). Considering all the existing evidence within the framework of our model, nitrogen deposition appears to be a further and important largescale driver of global change with predictable impacts in herbivorous species in addition to primary producers.

\section{ACKNOWLEDGEMENTS}

We acknowledge the support of the European Commission Framework Programme (FP) 7 via the Integrated Project STEP (grant no. 244090) and the Academy of Finland via the Finnish Research Programme for Climate Change (FICCA) to the project A-LA-CARTE led by Tim Carter. We express our gratitude to Matti Virtala and the Finnish Lepidopterological Society for permission to use distribution atlas data from 'Hyönteistietokanta'. The study has been supported by the TRY initiative on plant traits (http://www.trydb.org). The TRY initiative and database is hosted, developed and maintained by J. Kattge and G. Bönisch (Max-Planck-Institute for Biogeochemistry, Jena, Germany). Data on leaf nitrogen content data were provided by Hans Cornelissen, Joseph Craine, Eric Garnier, Jens Kattge, Peter Reich and Benjamin Yguel (for the complete list of original studies see Appendix S2). TRY is/has been supported by DIVERSITAS, IGBP, the Global Land Project, the UK Natural Environment Research Council (NERC) through the programme QUEST (Quantifying and Understanding the Earth System), the French Foundation for Biodiversity Research (FRB), and GIS 'Climat, Environnement et Société' France. Comments by Michiel WallisDeVries and an anonymous referee helped to improve the manuscript.

\section{REFERENCES}

Altermatt, F. (2010) Climatic warming increases voltinism in European butterflies and moths. Proceedings of the Royal Society B: Biological Sciences, 277, 1281-1287.

Angert, A.L., Crozier, L.G., Rissler, L.J., Gilman, S.E., Tewksbury, J.J. \& Chunco, A.J. (2011) Do species' traits predict recent shifts at expanding range edges? Ecology Letters, 14, 677-689.

Awmack, C.S. \& Leather, S.R. (2002) Host plant quality and fecundity in herbivorous insects. Annual Review of Entomology, 47, 817-844.
Betzholtz, P.E., Pettersson, L.B., Ryrholm, N. \& Franzén, M. (2013) With that diet, you will go far: trait-based analysis reveals a link between rapid range expansion and a nitrogen-favoured diet. Proceedings of the Royal Society B: Biological Sciences, 280, 20122035.

Biesmeijer, J.C., Roberts, S.P.M., Reemer, M., Ohlemüller, R., Edwards, M., Peeters, T., Schaffers, A.P., Potts, S.G., Kleukers, R., Thomas, C.D., Settele, J. \& Kunin, W.E. (2006) Parallel declines in pollinators and insect-pollinated plants in Britain and the Netherlands. Science, 313, 351-354.

Bobbink, R., Hicks, K., Galloway, J., Spranger, T., Alkemade, R., Ashmore, M., Bustamante, M., Cinderby, S., Davidson, E., Dentener, F., Emmett, B., Erisman, J.W., Fenn, M., Gilliam, F., Nordin, A., Pardo, L. \& De Vries, W. (2010) Global assessment of nitrogen deposition effects on terrestrial plant diversity: a synthesis. Ecological Applications, 20, 30-59.

Botts, E.A., Erasmus, B.F.N. \& Alexander, G.J. (2012) Methods to detect species range size change from biological atlas data: a comparison using the South African Frog Atlas Project. Biological Conservation, 146, 72-80.

Bowden, J.J., Eskildsen, A., Hansen, R.R., Olsen, K., Kurle, C.M. \& Høye, T.T. (2015) High-arctic butterflies become smaller with rising temperatures. Biology Letters, 11, 20150671.

Burnham, K.B. \& Anderson, D.R. (2002) Model selection and multimodel inference. A practical information-theoretic approach, 2nd edn. Springer, New York.

Carvalheiro, L.G., Kunin, W.E., Keil, P., Aguirre-Gutiérrez, J., Ellis, W.N., Fox, R., Groom, Q., Hennekens, S., Van Landuyt, W., Maes, D., Van de Meutter, F., Michez, D., Rasmont, P., Ode, B., Potts, S.G., Reemer, M., Roberts, S.P., Schaminée, J., WallisDeVries, M.F. \& Biesmeijer, J.C. (2013) Species richness declines and biotic homogenisation have slowed down for NW-European pollinators and plants. Ecology Letters, 16, 870-878.

Ceulemans, T., Merckx, R., Hens, M. \& Honnay, O. (2013) Plant species loss from European semi-natural grasslands following nutrient enrichment - is it nitrogen or is it phosphorus? Global Ecology and Biogeography, 22, 73-82.

Davis, R.B., Õunap, E., Javoiš, J., Gerhold, P. \& Tammaru, T. (2013) Degree of specialization is related to body size in herbivorous insects: a phylogenetic confirmation. Evolution, 67, 583-589.

Dennis, R.L.H., Shreeve, T.G., Arnold, H.R. \& Roy, D.B. (2005) Does diet breadth control herbivorous insect distribution size? Life history and resource outlets for specialist butterflies. Journal of Insect Conservation, 9, 187-200.

Dirnböck, T., Grandin, U., Bernhardt-Römermann, M., Beudert, B., Canullo, R., Forsius, M., Grabner, M.T., Holmberg, M., Kleemola, S., Lundin, L., Mirtl, M., Neumann, M., Pompei, E., Salemaa, M., Starlinger, F., Staszewski, T. \& Uziebło, A.K. (2013) Forest floor vegetation response to nitrogen deposition in Europe. Global Change Biology, 20, 429-440. 
Dise, N.B., Ashmore, M., Belyazid, S. et al. (2011) Nitrogen as a threat to European terrestrial biodiversity. The European nitrogen assessment. Sources, effects and policy perspectives (ed. by M.A. Sutton, C.M. Howard, J.W. Erisman, et al.), pp. 463-494. Cambridge University Press, Cambridge.

Dornelas, M., Gotelli, N.J., McGill, B., Shimadzu, H., Moyes, F., Sievers, C. \& Magurran, A. (2014) Assemblage time series reveal biodiversity change but not systematic loss. Science, 344, 296-299.

Duplouy, A., Ikonen, S. \& Hanski, I. (2013) Life history of the Glanville fritillary butterfly in fragmented versus continuous landscapes. Ecology and Evolution, 3, 5141-5156.

Duru, M., Ansquer, P., Jouany, C., Theau, J.P. \& Cruz, P. (2010) Comparison of methods for assessing the impact of different disturbances and nutrient conditions upon functional characteristics of grassland communities. Annals of Botany, 106, 823-831.

Ellenberg, H., Weber, H.E., Düll, R., Wirth, V., Werner, W. \& Paulissen, D. (1991) Zeigerwerte von Pflanzen in Mitteleuropa. Scripta Geobotanica, 18, 1-258.

Elser, J.J., Sterner, R.W., Gorokhova, E. et al. (2000) Biological stoichiometry from genes to ecosystems. Ecology Letters, 3, 540-550.

Fagan, W.F., Siemann, E., Mitter, C., Denno, R.F., Huberty, A.F., Woods, H.A. \& Elser, J.J. (2002) Nitrogen in insects: implications for trophic complexity and species diversification. The American Naturalist, 160, 784-802.

Finnish Museum of Natural History. (2013) Hyönteistietokanta. Available at: http://hyonteiset.luomus.fi/insects/ main/EntDatabase.html (accessed 13 December 2013).

Fridley, J.D., Lynn, J.S., Grime, J.P. \& Askew, A.P. (2016) Longer growing seasons shift grassland vegetation towards more-productive species. Nature Climate Change, 6, 865-868.

Fujita, Y., van Bodegom, P.M. \& Witte, J.P.M. (2013) Relationships between nutrient-related plant traits and combinations of soil $\mathrm{N}$ and $\mathrm{P}$ fertility measures. PLoS One, 8, e83735.

Galloway, J.N., Townsend, A.R., Erisman, J.W., Bekunda, M., Cai, Z., Freney, J.R., Martinelli, L.A., Seitzinger, S.P. \& Sutton, M.A. (2008) Transformation of the nitrogen cycle: recent trends, questions, and potential solutions. Science, 320, 889-892.

Guisan, A. \& Zimmermann, N.E. (2000) Predictive habitat distribution models in ecology. Ecological Modelling, 135, 147-186.

Hanski, I.A. (2011) Eco-evolutionary spatial dynamics in the Glanville fritillary butterfly. Proceedings of the National Academy of Sciences USA, 108, 14397-14404.

Hendriks, R.J.J., Carvalheiro, L.G., Kleukers, R.M.J.C. \& Biesmeijer, J.C. (2013) Temporal-spatial dynamics in Orthoptera in relation to nutrient availability and plant species richness. PLoS One, 8, e71736.

Hodgson, J.G., Montserrat-Martí, G., Charles, M. et al. (2011) Is leaf dry matter content a better predictor of soil fertility than specific leaf area? Annals of Botany, 108, 1337-1345.

Johnson, J.B. \& Omland, K.S. (2004) Model selection in ecology and evolution. Trends in Ecology and Evolution, 19, 101-108.

Kaplan, I. \& Denno, R.F. (2007) Interspecific interactions in phytophagous insects revisited: a quantitative assessment of competition theory. Ecology Letters, 10, 977-994.

Kattge, J., Díaz, S., Lavorel, S. et al. (2011) TRY - a global database of plant traits. Global Change Biology, 17, 29052935.

Lindström, J., Kaila, L. \& Niemelä, P. (1994) Polyphagy and adult body size in geometrid moths. Oecologia, 98, 130132.

Mattson, W.J. (1980) Herbivory in relation to plant nitrogen content. Annual Review of Ecology and Systematics, 11, 119-161.

Nieminen, M., Rita, H. \& Uuvana, P. (1999) Body size and migration rate in moths. Ecography, 22, 697-707.

Nordin, A., Strengbom, J., Witzell, J., Näsholm, T. \& Ericson, L. (2005) Nitrogen deposition and the biodiversity of boreal forests: implications for the nitrogen critical load. Ambio, 34, 20-24.

Nylin, S. \& Svärd, L. (1991) Latitudinal patterns in the size of European butterflies. Holarctic Ecology, 14, 192-202.

Öckinger, E., Hammarstedt, O., Nilsson, S.G. \& Smith, H.G. (2006) The relationship between local extinctions of grassland butterflies and increased soil nitrogen levels. Biological Conservation, 128, 564-573.

Pan, W. (2001) Akaike's information criterion in generalized estimating equations. Biometrics, 57, 120-125.

Paradis, E. (2006) Analysis of phylogenetics and evolution with $R$. Springer, New York.

Pereira, H.M., Leadley, P.W., Proenca, V. et al. (2010) Scenarios for global biodiversity in the 21st century. Science, 330, 1496-1501.

Pimm, S.L., Jenkins, C.N., Abell, R., Brooks, T.M., Gittleman, J.L., Joppa, L.N., Raven, P.H., Roberts, C.M. \& Sexton, J.O. (2014) The biodiversity of species and their rates of extinction, distribution, and protection. Science, 344, 1246752. doi:10.1126/science.

Pitcairn, C.E.R., Fowler, D., Leith, I.D., Sheppard, L.J., Sutton, M.A., Kennedy, V. \& Okello, E. (2003) Bioindicators of enhanced nitrogen deposition. Environmental Pollution, 126, 353-361.

Pöyry, J., Luoto, M., Heikkinen, R.K., Kuussaari, M. \& Saarinen, K. (2009) Species traits explain recent range shifts of Finnish butterflies. Global Change Biology, 15, 732-743.

Pöyry, J., Leinonen, R., Söderman, G., Nieminen, M., Heikkinen, R.K. \& Carter, T.R. (2011) Climate-induced increase of moth multivoltinism in boreal regions. Global Ecology and Biogeography, 20, 289-298.

R Core Team. (2013) R: a language and environment for statistical computing. R Foundation for Statistical Computing, Vienna, Austria. 
Ruoho-Airola, T., Hatakka, T., Kyllönen, K., Makkonen, U. \& Porvari, P. (2014) Temporal trends in the bulk deposition and atmospheric concentration of acidifying compounds and trace elements in the Finnish Integrated Monitoring catchment Valkea-Kotinen during 1988-2011. Boreal Environmental Research, 19, 31-46.

Schaffers, A.P. \& Sykora, K.V. (2000) Reliability of Ellenberg indicator values for moisture, nitrogen and soil reaction: a comparison with field measurements. Journal of Vegetation Science, 11, 225-244.

Schtickzelle, N., Mennechez, G. \& Baguette, M. (2006) Dispersal depression with habitat fragmentation in the bog fritillary butterfly. Ecology, 87, 1057-1065.

Sekar, S. (2012) A meta-analysis of the traits affecting dispersal ability in butterflies: can wingspan be used as a proxy? Journal of Animal Ecology, 81, 174-184.

Slade, E.M., Merckx, T., Riutta, T., Bebber, D.P., Redhead, D., Riordan, P. \& Macdonald, D.W. (2013) Life-history traits and landscape characteristics predict macro-moth responses to forest fragmentation. Ecology, 94, 1519-1530.

Stevens, V.M., Trochet, A., Van Dyck, H., Clobert, J. \& Baguette, M. (2012) How is dispersal integrated in life histories: a quantitative analysis using butterflies. Ecology Letters, 15, 74-86.

Stiling, P.D. (1987) The frequency of density dependence in insect host-parasitoid systems. Ecology, 68, 844-856.

Tao, L.L., Berns, A.R. \& Hunter, M.D. (2014) Why does a good thing become too much? Interactions between foliar nutrients and toxins determine performance of an insect herbivore. Functional Ecology, 28, 190-196.

Thomas, C.D., Cameron, A., Green, R.E. et al. (2004) Extinction risk from climate change. Nature, 427, 145-148.

Thomas, J.A., Telfer, M.G., Roy, D.B., Preston, C.D., Greenwood, J.J., Asher, J., Fox, R., Clarke, R.T. \& Lawton, J.H. (2004) Comparative losses of British butterflies, birds, and plants and the global extinction crisis. Science, 303, 1879-1881.

Throop, H.L. \& Lerdau, M.T. (2004) Effects of nitrogen deposition on insect herbivory: implications for community and ecosystem processes. Ecosystems, 7, 109-133.

WallisDeVries, M.F. (2014) Linking species assemblages to environmental change: moving beyond the specialist-generalist dichotomy. Basic and Applied Ecology, 15, 279-287.

WallisDeVries, M.F. \& van Swaay, C.A.M. (2006) Global warming and excess nitrogen may induce butterfly decline by microclimatic cooling. Global Change Biology, 12, 16201626.
Warren, M.S., Hill, J.K., Thomas, J.A., Asher, J., Fox, R., Huntley, B., Roy, D.B., Telfer, M.G., Jeffcoate, S., Harding, P., Jeffcoate, G., Willis, S.G., Greatorex-Davies, J.N., Moss, D. \& Thomas, C.D. (2001) Rapid responses of British butterflies to opposing forces of climate and habitat change. Nature, 414, 65-69.

White, T.C.R. (1993) The inadequate environment: nitrogen and the abundance of animals. Springer Verlag, Berlin.

Winter, M., Schweiger, O., Klotz, S., Nentwig, W., Andriopoulos, P., Arianoutsou, M., Basnou, C., Delipetrou, P., Didziulis, V., Hejda, M., Hulme, P.E., Lambdon, P.W., Pergl, J., Pysek, P., Roy, D.B. \& Kühn, I. (2009) Plant extinctions and introductions lead to phylogenetic and taxonomic homogenization of the European flora. Proceedings of the National Academy of Sciences USA, 106, 2172121725.

Yguel, B., Bailey, R., Tosh, N.D., Vialatte, A., Vasseur, C., Vitrac, X., Jean, F. \& Prinzing, A. (2011) Phytophagy on phylogenetically isolated trees: why hosts should escape their relatives. Ecology Letters, 14, 1117-1124.

\section{SUPPORTING INFORMATION}

Additional supporting information may be found in the online version of this article at the publisher's web-site:

Appendix S1 Details of building the phylogenetic hypothesis and Figs S1-S14.

Appendix S2 A list of the literature used in gathering trait data of butterflies and moths, with some representative examples of host plant use (Table S1). An analysis of the relationship between plant foliar nitrogen content and Ellenberg nitrogen $(\mathrm{N})$ indicator values (Fig. S15) and a list of the original papers that were used in gathering the foliar nitrogen data from the TRY database.

Appendix S3 Results of multimodel inference for the population trend (1993-2012) of butterflies and moths as the response variable, with all variables and models shown (Table S2).

Appendix S4 Figures S16-S18.

\section{BIOSKETCH}

Juha Pöyry is a research scientist at the Finnish Environment Institute who has experience in insect ecology, conservation and biodiversity. He is currently working on issues ranging from the impacts of climate change and habitat loss on insect communities to the management and restoration of semi-natural habitats.

Editor: Jeremy Kerr 